\title{
'There is still a long way to go to be solidly marvellous': professional identities, performativity and responsibilisation arising from the SEND Code of Practice 2015
}

\begin{abstract}
Special educational needs and disability (SEND) professionalism can be seen as a microcosm of the wider policy arena where traditional policy frameworks of professionalism and bureaucracy are challenged by frameworks of managerialism, consumerism and individual rights and where the neoliberal policy technologies of performativity and responsibilisation challenge and change collaborative working practices and professional identities. The recent introduction of the statutory SEND Code of Practice 2015 in England brings this transformation into relief. An exploratory qualitative interview study highlights how individual professionals respond to, are changed by and sometimes resist these demands.
\end{abstract}

\section{Introduction: the new SEND policy context and implications for a demanded professionalism}

Special educational needs and disability (SEND) professionalism can be seen as a microcosm of the wider policy arena where traditional policy frameworks of professionalism and bureaucracy are challenged by frameworks of managerialism, consumerism and individual rights and where the neoliberal policy technologies of performativity and responsibilisation challenge and change collaborative working practices and professional identities. The newly-statutory SEND Code of Practice (CoP) 2015 for England, jointly issued by the Department for Education and Department of Health (DfE and DoH, 2015), brings this transformation into relief.

The 2015 Code places children, young people and their families, rather than professionals, at the heart of the SEND identification, provision and reviewing processes. It requires local authorities (LAs) to 'have regard to the views, wishes and feelings' (CoP, 1.1) of families, not only concerning their individual provision, but also relating to the commissioning of local services. A second new core principle is the requirement for education, social care and health sector providers to work together more closely, with the Code prescribing how LAs and clinical commissioning groups (CCGs) will have to collaborate at a service commissioning level and at individual user level through the newly-introduced Education, 
Health and Care (EHC) Plan. The EHC Plan replaces the former Statement of special educational needs and is to be co-constructed by professionals from all involved agencies as well as the parents and/or carers under the supervision of dedicated LA staff. Significant changes to practice include: (1) an extension of the applicable age range (now covering 0-25 years) to address recognised problems around early identification, as well as inadequate transition into adult supported or independent living for young people with SEND; (2) the introduction of the Local Offer, detailing all the services and provision that can be accessed locally by families; and (3) the opportunity for holding personal budgets. For educational settings, it prescribes (4) the replacement of the social, emotional and behaviour difficulties (SEBD) area of need with social, emotional and mental health (SEMH); and (5) the merging of School Action and School Action Plus into a single SEN Support category. For teachers, the most significant change is that they are specifically and explicitly charged with the primary responsibility for the progress and wellbeing of each child in their class, with the special educational needs co-ordinator (SENCO) adopting a more strategic leadership role.

The 2015 Code is a prescriptive policy and accompanied by powerful systems of surveillance and is likely to generate in professionals 'a constant awareness of being held accountable' (Braun, Maguire \& Ball, 2010, p.554). This surveillance is not only or mainly instigated by new accountability regimes (in the form of the joint Ofsted/Quality Care Commission local area SEND inspection for example), but rather by policy technologies which determine not merely what people do, but also change who they are (Ball, 2015). Professional identities in this view are reaffirmed or remade in response to policy innovation and are shaped by professional standards which produce a 'demanded' professionalism that focuses predominantly on professional action, rather than an 'enacted' professionalism which additionally focuses on intellectual and attitudinal (motivation, morale, values) development of individuals (Evans, 2011). A demanded professionalism produces 'constructed narratives of personal growth on a journey towards accomplishment' (Watson \& Drew, 2015, p.458) which can never be achieved but is always to be pursued. The desire to become 'accomplished' does not merely refer to the knowledge and skills developed by experienced professionals, but also to their dispositions and concerns for continual selfdevelopment through which their identities are constructed and performed.

In this article I draw on a recently completed exploratory interview study to consider how the SEND Code of Practice 2015 (DfE and DoH, 2015) challenges and changes professional practices and identities in the presence of such a demanded professionalism. I adopt the language used in the 2015 Code but acknowledge that some of the terminology is 
problematic and is challenged by those opposed to deficit-driven constructions of difference (Runswick-Cole \& Hodge, 2009). I use the generic term SEND professional when referring to those whose work is partly or wholly focused on meeting the needs of children identified with SEND. Class teachers, social workers and health workers may have no particular prior interest or expertise in SEND, but their roles - sometimes as a consequence of policy changes - increasingly involve working with this group of learners. SEND professionals also include those with a particular focus on SEND, for example SENCOs in charge of the strategic development of SEND provision in schools, SEND advisors and caseworkers who focus on the statutory assessment and review work at local authority level, SEND specialist teachers and support staff from LAs and schools providing front-line services, and some health professionals who have specialised in this area. What unites them is that they are all 'public professionals' (Murray, 2013) whose professional practices and identities are altered through neoliberal policy making (Ball, 2015).

In what follows I first provide a context for my analysis by discussing neoliberal policy technologies which place increased accountability and responsibility demands on individual SEND professionals. I then problematise the expectation that those charged with progressing the inclusion agenda, which includes SEND professionals, should work on themselves and their underlying beliefs and attitudes (Black-Hawkins \& Florian, 2012, Liasidou, 2012). In the second part of the paper I document and discuss how these themes are reflected in professionals' discourse and experiences relating to the introduction of the SEND CoP 2015.

\section{Neoliberal policy technologies}

In neoliberal policy regimes traditional policy technologies such as professionalism and bureaucracy are replaced by technologies of managerialism, performativity and responsibilisation (Ball, 2015; Wright, 2012). I briefly review these technologies in preparation for exploring how individuals working under the SEND CoP 2015 are subjected to and subject themselves to these newer technologies.

Managerialism refers to the organisational management of public services along the lines of 'new public management' (NPM) devised in the 1990s and seen as a way of improving the 'implementation gap' between policy intention and realisation (Banks, 2014). NPM refers to the micro-management of the public sector by government; the formulation of specified criteria and standards of performance; an increase of competition within the public sector and between it and the private sector; and private sector forms of management (Dorey, 
2014). Managerialism is both an ideology and mode of organising the delivery of public services. It is demonstrated in public sector entrepreneurship, devolved budgets and institutional competition. It reconfigures professional identities through mechanisms of institutional loyalty and rivalry; individuals are now concerned with managing the institutional image, with directing their actions to meet personal and organisational performance indicators, and with demonstrating budget consciousness as an expression of professionalism. The consequences may be reductionist thinking about 'what counts', the undermining of collaborative working and distorted priorities. It may also entail 'ritual practices' that ensure individuals are seen to be carrying out requirements and forms of cheating (Cribb, 2009).

Performativity has been conceptualised in a variety of ways. In one model (Ball, 2003), it is related to three features: interventionist regulations, enforced by an audit and target culture, and set in a market environment. Individuals are required to be responsive and flexible and to monitor themselves and their performance. These features are all more explicitly present in the 2015 Code. Performativity addresses the notions that what professionals do measures the worth of their organisation and that an individual's worth and value is judged by measures of productivity and output (Adams, 2014). Whilst this may provide opportunities for some to demonstrate their effectiveness and produce feelings of achievement and success, in others it will produce turmoil, a lack of authenticity and antagonism. One significant feature of performativity is a revised ethical system which exchanges the older values of professional judgement and co-operation to those of institutional self-interest and pragmatic decision making (Ball, 2003). Performativity is a mechanism that may work against inclusive aspirations as it is clear to professionals who are subjected to and subject themselves to performative evaluations that children identified with SEND might challenge their 'professionalism' if this is measured by outcomes captured in league tables and the progress individuals make against normative targets. Institutional self-interest also works directly against the heightened expectations for effective interagency partnership working so clearly articulated in the 2015 Code.

A different but related conception of performativity (Butler, 2005; Jackson \& Mazzei, 2012) highlights linguistic action where what is said and articulated is not merely seen as a performance by an individual, but a 'performativity' that constitutes the subject in its desire for recognition. Recurring but subtly changing reiterations of what is said unsettle stabilising categories that seek to normalise and regulate and instead produce the space for conflicting subjectivities that disrupt stable identity categories. Performativity in this conception makes 
visible the constitution of subjectivities and emphasises professional identity as an effect of practice rather than practice being an expression of it. Here performativity emphasises incoherence and that individuals neither fully give in to the normative categories that seek to contain them, nor do they completely refuse them.

The concept of responsibilisation derives from Foucault (1982) and critiques a defining feature of neoliberal policy reform. It makes the economically self-interested individual responsible and accountable for their own actions, achievements and wellbeing. Importantly,

Governments advocating neoliberal market forces act not through mechanisms of social control and subordination of the will, but through the promotion of subjectivities, the constructions of ... ambitions, and the activation of guilt, anxiety, envy and disappointment....urging a constant scrutiny of our interactions...a constant judgement of their consequences. (Rose, 1989, p.208)

Responsibilisation as a policy technology refers to the internalisation of neoliberal ideals which generate forms of self-management that require professionals to 'submit themselves to a gruelling regime of self-criticism, self-discipline and self-assessment in order to keep external forces of control at arm's length' (Wright, 2012, p.291). Responsibilisation usually results in self-doubt and personal anxiety, rather than in open debate and dissent; responsibilised professionals are not only highly committed and creative in enacting policy, but also committed 'to work on themselves to do it well' (Ball et al., 2012, p.138). The presence of self-surveillance and self-assessment techniques generate accountability practices that ensure that professionals can evidence and account for their actions. However, this characterisation of a responsibilised professional identity and practice may not account sufficiently for the 'widespread ties, dependencies, and duties to others' (Trnka and Trundle, 2014, p.4) that many professionals demonstrate and are motivated by. The authors argue that whilst a much-needed re-conceptualisation of professional responsibility must acknowledge the critique provided by the concept of responsibilisation, it needs to be extended by cosidering an equally present 'ethics of care' where 'obligations, duties and reciprocities [...] lie alongside, challenge, or are reconciled with those of responsibilised neoliberal subjects' (p.6). An ethics of care contrasts the idealised notion of the isolated individual often implied in neoliberal perspectives, and focuses on relationships. It draws attention to concepts such as loyalty, trust and empowerment. This requires professionals to consider multiple voices in decision-making processes and to learn how to be attentive and responsive (Shapiro \& Stefkovich, 2011). Mature ethical professional action necessitates 
holding the two conceptions of professionals as responsible moral agents and responsibilised subjects in creative tension, rather than allowing one to subsume the other. It asks of professionals to negotiate a path of resistance and accommodation and affirms professionals as moral agents. Acknowledging these diverging conceptions of responsibility and responsibilisation may also offer a way of approaching the sometimes highly charged debate in literature around the role of SEND professionals in contributing to or undermining inclusive ideals (Ainscow, 2007; Liasidou, 2012; Slee, 2011), which I explore further in the following section.

\section{The contested relationship between the inclusion agenda and SEND provision}

The stories of special and of inclusive education in England are complex and contested, and 'characterised by considerable ambiguity' (Dyson, 2005, p.65). SEND professionals are regularly criticised for protecting their own interests, as well as for attitudes and beliefs which undermine efforts towards fully including children identified with SEND in mainstream settings (Liasidou, 2012). One reason for this apparent undermining is the perceived incompatibility of the inclusion agenda with the standards agenda, where schools are required to both improve their academic results and also to include children who demand high levels of support in the context of diminishing resources. Those who understand inclusion to be a process concerned with identifying and removing barriers to the presence, participation and achievement of all (Ainscow, 2007) reject the idea that inclusion and standards agendas are incompatible. Effective inclusion in this view is predicated on values and a pedagogy that responds positively to student diversity, seeing individual differences not as problems to be fixed, but as opportunities for enriching learning. Factors which may stop inclusion at within-school, between-school and beyond-school levels need identifying and addressing and any arising conflicts and disturbances need to be dealt with constructively as a stimulus to challenge thinking and as an important management tool for developing professional practice (Ainscow, Booth \& Dyson, 2006). This view argues that what is needed in terms of continuous professional development (CPD) is not so much the technical know-how that teachers and practitioners often presume they need and lack, but rather an examination and a strengthening of underlying attitudes and beliefs (BlackHawkins \& Florian, 2012) which in this view is faulty in many front-line professionals. However, these demands are as likely to generate self-criticism, self-doubt and personal anxiety in responsibilised professionals as they are to contribute to transforming an exclusionary system. 
Having provided a thematic context by exploring neoliberal policy technologies as well as the contested relationship between inclusion ideals and SEND practices, I now explore responses to the SEND CoP 2015 by professionals who were directly involved in the early enactment of policy changes.

\section{Methodology}

I draw on an exploratory empirical project which aimed to listen and learn from the early experiences of SEND professionals collaborating under the statutory guidance of the 2015 Code. The study was conducted between October 2014 and February 2015 in accordance with the guidelines of the British Education Research Association (BERA, 2011). I employed single, in-depth, semi-structured interviews, lasting for approximately one hour each, which were recorded and transcribed for qualitative analysis. The 16 participants occupied a range of professional roles relating to SEND from across education, health and social care agencies in 4 local authorities in England. The voluntary participation from 3 class teachers, 3 SENCOs, 4 SEND caseworkers, 3 SEND advisors and commissioners, 2 social workers and a child psychiatrist was secured by a snowballing system of recommendations. Where the particular role of the participant is relevant, I indicate this in brackets and I use pseudonyms throughout. The project asked participants broadly discuss their early experiences of intensified partnership working under the new Code; to reflect more generally about the enablers and barriers to partnership working; to identify specific new challenges encountered; and to discuss any ethical concerns arising. Data was analysed by drawing on constructivist grounded theory approaches (Charmaz, 2014). For initial coding, I used a software programme for qualitative analysis (NVivo10). In this article, I utlise selective data and have applied the critical lenses of performativity and responsibilisation to aid further analysis.

\section{Performativity demands and partnership working}

I first outline how performativity demands shape participants' professional identities and influence approaches to partnership working. Many of the participants discuss the importance they place on contributing to the interests and positive reputation of their own organisation and that this is sometimes in tension with and may need to be privileged over collaborative concerns. SENCO ELLA for example values building good relationships with partners but also highlights the benefits of this concern for her school: 
When you've got those positive relationships, it can work to your school's advantage. [...] I don't do it in order for that to happen, but I'm aware that possibly that does make things move. (ELLA)

Social worker AMY also reflects on how to maximise the interests for her organisation:

We are not expert in new policies to do with SEND, so we just go with the flow but try to put our particular angle or experience or agenda in, so that it meets our own agenda and our own Child Protection Plan. I will always be looking to set some stretching targets, because that is in the child's best interest and social care's best interest as well. (AMY)

Documenting, and being seen to be documenting, their work is also a major performative concern:

The thing I was asked [during a recent OFSTED inspection] was, 'Can you show the impact of this group?' Luckily, that looked quite good: 'Here, look, I can show'...but it wasn't documented. (HANNA)

SEND caseworker OLGA discusses the expectation to fully engage parents in the formulation of the new EHC Plan, but points out that sometimes parents repeatedly do not come to meetings. She knows that there is little she can do, but that she has to ensure that these attempts are carefully recorded because 'then I've got documentary evidence that we gave them every opportunity'. Some participants go as far as following directives to complete forms, not because they are convinced of their usefulness, but rather because they know that this is important for partners:

I always try and fill in my forms when I am reminded because I know that's their job and they will be in trouble if they don't get their forms filled in. (PEETA)

In this case, second-order activities of performance monitoring and management replace the valued first-order activities of direct engagement with colleagues and children (Ball, 2003).

A number of participants have expressed their anxieties about contributing to or formulating the new EHC Plans, and many of these anxieties relate to performativity demands. OLGA is new to writing Plans and has no prior experience of writing Statements:

I think we'll get better at those. I mean, [...] it's taking me ages because we're doing it in a slightly different way... and we're all slow at it. (OLGA) 
NADIA in the same team has prior experience, but is equally anxious:

You could do it [writing a Statement] in about half a day, maybe. Once you knew what you were doing, you could do it. These are taking so much longer. I think more than a day per one, at the moment, ... and it's hard to explain why...(NADIA)

It was clear though that she felt the need to explain and justify why the EHC Plans took such a long time to construct.

SEN caseworker LILLY recognises the demands she makes on her school-based colleagues who have to contribute to the Plan and expresses empathy:

A lot of these people haven't written reports like this before, outcome focused. I think it's fear of the professionals [...] and I think that needs to be taken into account, I think we need to be quite sensitive. (LILLY)

Here, she resists performativity demands on behalf of colleagues. However,, she also provides a powerful example of what it means to perform as policy subject in her role as partner, which requires her to insist on accountability for the high needs funding given to a school:

I have to really be like, 'This is what the child needs, tell me what figure do you need in order to do that'... 'You're saying you need $£ 30,000$ or $£ 40,000$ ? Right, for $£ 40,000$ these are the things that need to be implemented - it's not going to just be a pot of money'. (LILLY)

LILLY describes imposing accountability demands on partners and has become an instrument of a performative regime. Whilst she does not appear to be troubled by this, others have a different story to tell.

Health professional PEETA most clearly expresses how performativity demands, intensified in the current austerity regime, challenge professional identities as well as the value given to professional knowledge and expertise. This has been documented less frequently where children identified with SEND are concerned, but PEETA's comments demonstrate how SEND policy is now fully subsumed into neoliberal policy making and its attendant technologies (Tomlinson, 2012) and that individuals, as well as partnership working, are deeply challenged by it: 
There's a great level of complexity around each case, but that's not really taken into account in terms of the time that you're allocated to do the work. And that, you know, has become increasingly so with austerity. It's become like a factory...the powers that be that drive commissioning want worked face-to-face contacts measured, that's what is measured, but also the number of cases and how fast you see cases. So the drive is to get all the cases seen within eight weeks now, then you're expected to get rid of them within six to eight sessions. And you just can't with children with severe and enduring learning disabilities. And children with neuro-developmental impairments, at any one time, one-third of them are going to have a mental health problem anyway. So you can see that actually discharging them, which we have to...we're constantly being told to do now, is quite difficult. There's a lot of anxiety around about how you're seen to be performing. (PEETA)

PEETA challenges the notion of auditing for measuring effectiveness, where 'quality is reduced to that which is easily measurable' (Morrison \& Glenny, 2012, p.375) and identifies the temptation that that which can be measured becomes what is valued. She rejects attempts to reduce complex processes to measurable episodes and evokes memories of a different set of values and ways of partnership working:

In the past, clinicians could... choose which cases you wanted ... Now, you just get allocated anybody, your slot. So there used to be team discussions around cases as they were coming in, but they decided that that was very wasteful of time.

The valuing of managerial processes over professional self-determination and judgement affects her professional identity as well as her personal wellbeing:

So that really was very distressing to me and I felt, well, there was a parting of the ways there and I just... you know, I was actually seen as difficult and unhelpful to the management because I kept on saying that we needed measures that were fit for purpose [...] They don't value [professional expertise], that's the sad thing, it's not valued at all. What would be valued is if I did audit projects or worked on some management group that was looking into gap analysis or manage to get people working harder, something like that. But the clinical aspect and the specificity of the work that I do, there's no interest in it. No one has ever asked me about the quality of my work or asked any of the people that I work with, they're not really interested in it. (PEETA) 
PEETA highlights the significance of incremental changes in the development of individuals identified with considerable SEND ('I'm aware that, for me, something like that is very precious') that cannot be measured by performance indicators and are therefore not valued in a performative context. For her, there are personal consequences as she is not willing to accept the revised ethical system under which she is expected to operate:

I didn't feel that I could manage a team when I knew that they couldn't actually do the work in the time available. I saw colleagues becoming physically unwell or getting stress-related conditions, and staying late, and I always felt that if I can't do it, then I shouldn't expect other people to do it. The consequence for me is that I have to leave. (PEETA)

Performativity changes what SEND professionals do and also who they are. Their identities are defined through a range of accountabilities rather than by professional expertise, and by making judgements about their own and others' performance and worth. They expect to justify how their time has been used and are troubled by the length of time certain new tasks take. They expect to document and be seen to be documenting their partnership activities in response to performative demands, but also demonstrate their ongoing desire for collaborative practice by accommodating the needs of partners who they recognise as being subjected to their own performative routines. Some offer themselves as instruments of performativity and redefine their identities accordingly, whilst others are deeply troubled and draw personal consequences.

Where well-intentioned professionals seek to avoid uncertainty, mistakes and likely 'failure', they will be tempted to construct themselves, in conversations with colleagues and parents, or in the public sphere as 'experts' who know what to do; and who therefore accept being told what to do by a knowledge-producing system that guides their practice, rather than living and acting a relational, reciprocal, open and inevitably uncertain professionalism (Urban et al., 2012). This is a very different professionalism from the one ELLA discusses where colleagues are 'trying to make sure that it's clear that they have worth and have earned their place at the table' by using sophisticated vocabulary to impress and intimidate. It is also a different professionalism from the one that caused HANNA to be 'standing on the edge' because she didn't know how to bring about a desired change and where the 'not knowing how' didn't align with her conception of an assured and accomplished professionalism.

\section{The responsibilised professional doing work on themselves}


ELLA makes an interesting observation:

For me, it's what I believe about education and what matters for children, and getting it right and being fair and always trying to think, 'Right, how can we move things on? What can we do to make this happen?' and genuinely trying to be as inclusive as we can. I think for some schools it's fear of their results going down or disruption in the class, but actually, that's not what it's all about. (ELLA)

For ELLA, there are considerations around values and high expectations of her own professionalism. There is also an acute awareness of operating in a competitive environment where accepting children with high needs is likely to affect league table positions and put a strain on resources. Most significantly, her remark is about responsibilisation, which is not necessarily recognised: 'always trying to think' and having to 'make this happen' in order to be inclusive as well as performative becomes an internalised responsibility for the individual professional, who has to 'work on herself' to first adopt and then remain in this frame of mind:

We know we've got the little quote in Ofsted saying how marvellous it is in terms of SEND children achievement and stuff, but actually, there's still a long way to go to really be solidly marvellous, I would say. (ELLA)

Social worker ISABELLA is grateful for managers who have 'challenged me on something that I haven't really thought about' and PEETA remarks that 'shamefully, I've not actually managed to read it' [the 2015 Code]. OLGA concedes that she is 'not 100 per cent yet' and HANNA also talks in responsibilised terms which focus on self-conduct:

It spurs me on to think I want to know more, I want to do it better, I want to be able to make things be more effective. (HANNA)

There is a very fine line here between demonstrating a dedicated professionalism which provides personal satisfaction as well as good outcomes for children identified with SEND, and being required to demonstrate a responsibilised disposition with the attending uncertainty of whether individuals are 'doing enough, doing the right thing, doing as much as others, or as well as others - constantly looking to improve, to be better, to be excellent' (Ball, 2003, p.220).

The striving to be excellent, and in HANNA's terms 'to be solidly marvellous', overrides clearly articulated personal dislikes, such as for example working in open-plan offices, hot- 
desking, and paperless e-filing. At this level also, individuals go along with the responsibilisation agenda: 'I don't like it, no, but I've made myself deal with it' (OLGA).

Individuals also take responsibility for character traits that they identify as problematic and they take the blame for negative outcomes:

Personally, I get passionate about what I'm doing, and I know that I become defensive, which doesn't always bring the best out in meetings. (NADIA)

I think I might be partly to blame because I don't think I completely understood the process. I know that I was annoying people [...] and I was hounding them. (ISABELLA)

I'm certainly conscious that this half term, by my own standards, I've fallen down from sheer pressure of work, not following things through properly [...], so I need to work out how to address that, and I'm conscious of that. (ELLA)

I was a complete waste at the tribunal I'm afraid, I shouldn't have gone in the first place. (NADIA)

It is important to note that for some, the recurring theme of responsibilisation is a positive experience of self-determination and ownership. Social worker AMY comments on the 'number of courses that we can self-select to go on' and is proud of the personal contribution she makes:

I play a significant part. I consider myself the number one advocate for the child and for their wellbeing, I am not there to just improve someone's academic achievement, I am not there just to ensure that they stay well and out of hospital, I feel my responsibilities are more holistic and wide-ranging, but also more fundamental. (AMY)

For her, the responsibilities that come with her role are welcome rather than limiting in shaping a positive professional (and likely personal) identity. This can only be achieved, however, by viewing her own role and position as privileged over and above those of partners in education and health to whom she attributes a more limited role. Her own confidence turns very quickly into judgement of those she feels do not take responsibility for themselves and with this articulates most explicitly a reconstructed responsibilised neoliberal subjectivity:

They are not very good with SMART planning, at coordinating meetings, at organising themselves, at juggling a caseload of $18-25$ cases so that they are all on the boil all the 
time... and the kind of skills you need therefore to be an effective social worker these days. There does need to be good management, but there needs to be good selfmanagement, too. (AMY)

Improvement officer FLORA extends this expectation to partnership working:

It is a legitimate expectation when you are in a partnership that you have a sense of mutual responsibility to offer the same, and to support each other, to be as good as you can be. (FLORA)

In this section I have identified responsibilised subjectivities and demonstrated how SEND professionals are engaged in improving and often in exhorting themselves or others 'to do it better'. They recognise that there 'is still a long way to go to really be solidly marvellous' and assume that it is the individual's responsibility to 'make this happen'. Individuals submit to working practices which are experienced as costly to personal wellbeing and take responsibility for undesirable character traits: 'The logics of 'improvement' make us better at what we are supposed to do, but at the same time they ensure that perfection is always out of reach and that there is more work to do on ourselves' (Ball, 2015, p.308).

\section{Multiple accountability demands}

For some participants, there is an additional challenge and sadness that just as they have made meaningful differences to children's lives, they have to let go of these responsibilities and relationships:

A child I'm working with at the moment has just got his EHC Plan. Well then, now the school is getting that, I have to back off. So you build up this relationship with the child and they get what they need and you go, 'Yeah!' and then you go, 'Right, goodbye'. (KEZIA)

Inclusion worker KEZIA here does not articulate a sense of responsibility arising from neoliberal ideals of accountability, but rather as an expression of affective care, which 'can exist in dialogical relationship' (Trina \& Trundel, 2014, p.8) without subsuming one another. This co-existence is also promoted by other participants:

When you've got deadlines and so many competing demands, it's very easy to forget the child in all of that. But that's what I always try and bring myself back to, actually. Is this right for them? Or am I doing this to make my own life easier? (ISABELLA) 
ISABELLA acknowledges that both care and performativity responsibilities make demands on her, and she allows one to challenge the other for a settlement she can live with. Multiple forms of accountability pull professionals in different directions but may also hold competing demands in balance (Ehrich et al., 2013) and offer a way out of the experienced impasse.

ELLA also articulates a nuanced understanding of her responsibility:

It is to do with saying, 'Well, let's just go for it'. And actually, no-one's head is going to be on the block if we don't meet this, we can show how far along this line we got in terms of developing this child's capacity to listen and take turns or whatever it is. But if all we're focusing on is the minimal, then we're shortchanging the child. (ELLA)

ELLA simultaneously accepts but also articulates resistance to performativity demands where they oppose her felt responsibility to have the highest of expectations as integral to promoting the best interests of the child and this opens up a space where she can exercise independent professional moral agency. ELLA, more than others seems to have a vocabulary for discussing conflicts and challenges in their complexity, and it appears to help her to set personal and professional boundaries, but also to remain engaged as a respected and sought-after partner:

It's to do with how people measure you up when you're in meetings, about the sorts of things you say and how you say them. So what your values are, in a way. (ELLA)

Responsibility originating in an ethics of care rather than arising from neoliberal responsibilisation views relationships as open-ended and as able to withstand conflict and uncomfortableness. Power is negotiated rather than shared because 'relations of care are not inherently equal but may allow for different degrees of dependence and need' (Trnka \& Trundle, 2014, p.8). By focusing on an ethics of care in the moment, questions of social justice or social inequality may be bracketed and offer the possibility of multiple framings of responsibility and the switching from troubling neoliberal logics of self-responsibility and selfimprovement to more appropriate forms of interpersonal responsibility and obligation. Some participants, more than others, have developed a degree of discernment of those multiple framings and draw on their ethical knowledge (Campbell, 2003) to decide which to privilege in the moment.

\section{Discussion of findings}


Neoliberal policy technologies are increasingly evidenced in SEND policy making and in mandated partnership working. Because of this, the 2015 SEND Code of Practice has unsurprisingly generated some anxiety and insecurity around 'not knowing' enough and 'maybe getting it wrong' in the processes of embedding new demands into existing structures and practices, and individuals are therefore anxious to know whether they do enough'. My participants reveal how new performativity demands impact often negatively on SEND professionals who work under the 2015 Code where the specific new demands placed on various partners is underwritten by the 'legitimate expectation' that individuals should be 'as good as they can be' in order to facilitate effective practice.

My participants feel particularly challenged where appropriate and pragmatic solutions because they save money, follow published guidelines, ensure parity for service users, make jobs manageable - may in fact not be the preferred courses of action for upholding the best interests of a particular child. They find themselves caught between applying universalised pronouncements outlined in a statutory Code and needing to construct personalised support for individual children and their families. Questions about what should be done continue to preoccupy SEND professionals because, despite increasing responsibilisation, the 2015 Code offers very limited answers to such questions, even though it has been promoted as offering a 'way out' of the bureaucratic entanglements front-line practitioners, in particular, find themselves in.

Liasidou (2012) identifies those advocating for full social and educational inclusion as being particularly conflicted, 'for they are expected to compromise contradictory policy agendas and align concerns for equity and social justice with neoliberal constructions of educational excellence' (p.47). Some of my participants indicate that those conflicts may not only or most acutely be experienced by those at 'the forefront of the struggles for inclusion' (p.47), but also by those who have their doubts about full inclusion, and especially those who are close to individual cases and also have strategic responsibilities which go beyond those cases (SENCOs and SEN officers for example). Whilst Liasidou describes an external struggle for inclusion and against an unjust system, my participants have expressed performativity and responsibilisation demands which are frequently internalised and individualised. These demands are often experienced as moral burdens which may constitute a form of oppressive practice which is missed where the focus is on broader structural injustices rather than on individual relationships (Cribb \& Gewirtz, 2012). 
Those participants who doubt that full inclusion is achievable and question whether it is always in the best interests of the child to remain in a mainstream classroom merely hint at this disquiet. In my small study, class teachers who now carry the greatest responsibility for meeting the needs of children identified with SEND are also those who have been least consulted and are most concerned. They are frequently silenced and sometimes blamed by other professionals in the partnership, and also by those who advocate full inclusion. What is asked of them is to do work on themselves, with little opportunity to articulate doubts and fears. Being responsibilised as a performative policy subject (Ball, 2015) appears to also require the SEND professional to view full inclusion as an objective of 'indisputable moral and ethical standing' (Liasidou, 2012, p.6) such that failure to accept this objective must be challenged.

\section{Conclusion}

This article considered the 2015 Code not principally as a container of instructional content which directs and limits professional practice, but rather as an active agent (Prior, 2008) and I was therefore interested not primarily in what the Code says, but in how it is employed and what it does to individuals who work under its directives. In my exploration of early professional experiences with the Code I disrupted the document's 'decidability' (Slee \& Allan, 2001, p.180) by rejecting its claimed status as a 'straightforward' (DfE, 2011, p.5) tool for providing professional guidance and explored how the Code is 'caught up in powerful political and economic dynamics' (Norwich, 2014, p.422) instead. These dynamics change and sometimes undermine - professional confidence and identities and challenge mandated partnership working due to often incompatible performativity demands. The participants in the reported study attest to the work on the self that is demanded of professionals in the process of responsibilisation. Some have also demonstrated that responsibilisation consistent with neoliberal ideals of accountability can exist in a dialogic relationship with the responsibilities arising from compassionate care and where, I would argue, compassionate care must include the care of self. Learning to distinguish between performativity as a terror and as a form of agency and distinguishing between responsibilisation as an oppressive form of self-conduct or a chosen ethics of care may lead to an act of resistance or else become a considered and compassionate response to the particularly challenging pupil group SEND professionals are dealing with. It may offer a 'way out of the impasse' to 'produce identity and meaning within the structural and discursive limitations of everyday practice' (Ball, 2015, p.309f). 


\section{References}

Adams, P. (2014) Policy and education (Abingdon, Routledge).

Ainscow, M. (2007) Taking an inclusive turn, Journal of Research in Special Educational Needs, 7 (1), 3-7.

Ainscow, M., Booth, T. and Dyson, A. (2006) Inclusion and the standards agenda:

Negotiating policy pressures in England, International Journal of Inclusive Education, 10 (4), 295-308.

Ball, S. J. (2003) The teacher's soul and the terrors of performativity, Journal of Education Policy, 18 (2), 215-228.

Ball, S. J. (2015) What is policy? 21 years later: Reflections on the possibilities of policy research, Discourse: Studies in the Cultural Politics of Education, 36 (3), 306-313.

Ball, S. J., Maguire, M. and Braun, A. (2012) How schools do policy: Policy enactments in secondary schools (London, Routledge).

Banks, S. (2014) Ethics: Critical and radical debates in social work (Bristol, Policy Press). BERA (British Educational Research Association) (2011) Ethical guidelines for educational research (London, BERA).

Black-Hawkins, K. \& Florian, L. (2012) Classroom teachers' craft knowledge of their inclusive practice, Teacher and Teaching: Theory and Practice, 18 (5), 567-584.

Braun, A., Maguire, M. and Ball, S. J. (2010) Policy enactments in the UK secondary school: Examining policy, practice and school positioning, Journal of Education Policy, 25 (4), 547560.

Butler, J. (2005) Giving an account of oneself (New York, NY, Fordham University Press).

Campbell, E. (2003) The ethical teacher (Maidenhead, Open University Press).

Charmaz, K. (2014) Constructing grounded theory ( $2^{\text {nd }}$ edn) (London, Sage).

Cribb, A. (2009) Professional ethics: Whose responsibility? In S. Gewirtz, P. Mahony, I. Hextall and A. Cribb (Eds) Changing teacher professionalism: International trends, challenges and ways forward (London, Routledge), 31-42.

Cribb, A., and Gewirtz, S. (2012) New welfare ethics and the remaking of moral identities in an era of user involvement, Globalisation, Societies and Education, 10 (4), 507-517.

DfE (Department for Education) (2011) Support and aspiration: A new approach to special needs and disability - a consultation (London, HMSO).

DfE and DoH (Department for Education and Department of Health) (2015) Special educational needs and disability Code of Practice: 0 to 25 Years. Available at: https://www.gov.uk/government/uploads/system/uploads/attachment_data/file/398815/SEND _Code_of_Practice_January_2015.pdf (accessed 30 July 2015).

Dorey, P. (2014) Policy Making in Britain ( $2^{\text {nd }}$ edn) (London, Sage).

Dyson, A. (2005) Philosophy, politics and economics? The story of inclusive education in England. In D. Mitchell (Ed.) Contextualising inclusive education: Evaluating old and new international perspectives (London, Routledge), 63-88

Ehrich, L. C., Klenowski, V., Harris, J., Smeed, J., Carrington, S. and Ainscow, M. (2013) Ethical leadership in a time of increasing accountability. Paper presented at the British Educational Research Association Conference, Sussex University, September 2013. 
Evans, L. (2011) The 'shape' of teacher professionalism in England: Professional standards, performance management, professional development and the changes proposed in the 2010 white paper, British Educational Research Journal, 37 (5), 851-870.

Foucault, M. (1982) The Subject and Power, Critical Inquiry, 8 (4), 777-795.

Jackson, Y. A. and Mazzei, L. A. (2012) Thinking with theory in qualitative research: Viewing data across multiple perspectives (Abingdon, Routledge).

Liasidou, A. (2012) Inclusive education, politics and policymaking (London, Continuum).

Morrison, M. and Glenny, G. (2012) Collaborative inter-professional policy and practice: In search of evidence, Journal of Education Policy, 27 (3), 367-386.Murray, D. (2013)

Professional school leadership: Dealing with dilemmas (London, Dunedin Academic Press).

Norwich, B. (2014) Changing policy and legislation and its effects on inclusive and special education: A perspective from England, British Journal of Special Education, 41 (4), 404425.

Prior, L. (2008) Repositioning documents in social research, Sociology, 42 (5), 821-836.

Rose, N. (1989) Governing the soul (London, Routledge).

Runswick-Cole, K. and Hodge, N. (2009) Needs or rights? A challenge to the discourse of special education, British Journal of Special Education, 36 (4), 198-203.Shapiro, J. P. and Stefkovich, J. A. (2011) Ethical leadership and decision making in education: Applying theoretical perspectives to complex dilemmas ( $3^{\text {rd }}$ edn) (Abingdon, Routledge).

Slee, R. and Allan, J. (2001) Excluding the included: A reconsideration of inclusive education, International Studies in Sociology of Education, 11 (2), 173-191.

Slee, R. (2005) Education and the politics of recognition: Inclusive education - an Australian snapshot. In D. Mitchell (Ed.) Contextualising inclusive education: Evaluating old and new international perspectives (London, Routledge), 139-165.

Slee, R. (2011) The irregular school: Exclusion, schooling and inclusive education (Abingdon, Routledge).

Tomlinson, S. (2012) The irresistible rise of the SEN industry, Oxford Review of Education, 38 (3), 267-286.

Trnka, S. and Trundle, C. (2014) Competing responsibilities: Moving beyond neoliberal responsibilisation, Anthropological Forum: A Journal of Social Anthropology and Comparative Sociology, 24 (2), 136-153.

Urban, M., Vandenbroeck, M., Van Laere, K., Lazzari, A. and Peeters, J. (2012) Towards competent systems in early childhood education and care: Implications for policy and practice, European Journal of Education, 47 (4), 509-526.

Watson, C. and Drew, V. (2015) Teachers' desire for career-long learning: Becoming 'accomplished' - and masterly, British Educational Research Journal, 41 (3), 448-461.

Wright, A. (2012) Fantasies of empowerment: Mapping neoliberal discourse in the coalition government's school policy, Journal of Education Policy, 27 (3), 279-294. 